\title{
Sumak Kawsay: ¿estrategia política o filosofía de vida?
}

\section{Sumak Kawsay: political strategy or philosophy of life?}

\author{
Segundo Morocho Ajila ${ }^{1}$ \\ segundo.morocho@ucuenca.edu.ec
}

\begin{abstract}
Resumen
El presente artículo busca analizar la construcción discursiva, de manera crítica, del Sumak Kawsay, la misma que se ha venido rigiendo como propuesta política y filosófica de la visión andina en Ecuador. Primeramente, se estudiarán a los actores políticos de los años 80 y 90 , y luego se contrastará con los preceptos de las políticas emprendidas por el actual régimen. En lo que respecta a la posición filosófica, que emerge del Sumak Kawsay, se analizará bajo el pensamiento occidental, con ventajas perceptibles sobre la filosofía eurocentrista. Finalmente, se estudiará la relación entre la praxis política actual ecuatoriana y la cultura andina.
\end{abstract}

\section{Palabras clave}

Sumak Kawsay, filosofía, cosmovisión andina, visión occidental.

\begin{abstract}
This article aims to analyze the critical discursive construction of the Sumak Kawsay, the same one that has been ruled as a political and philosophical proposal of the Andean vision in Ecuador. Firstly, the political actors of the 1980s and 1990s will be studied, and then contrasted with the precepts of the policies undertaken by the current regime. As for the philosophical position that emerges from Sumak Kawsay, it will be analyzed under Western thought, with perceptible advantages over Eurocentric philosophy. Finally, we will study the relationship between current Ecuadorian political praxis and Andean culture.
\end{abstract}

\section{Keywords}

Sumak Kawsay, philosophy, Andean worldview, Western vision.

Forma sugerida de citar: $\quad$ Morocho Ajila, Segundo (2017). Sumak Kawsay: ¿estrategia política o filosofía de vida? Universitas, XV(26), pp. 179-198.

1 Docente de la Universidad de Cuenca, Ecuador. ORCID iD http://orcid.org/0000-0001-7486-8177 


\section{Sumak Kawsay}

El Sumak Kawsay, también conocido como Buen Vivir, se convirtió en el eje central de la política ecuatoriana, el mismo que fue aprobado en la Constitución de 2008 (SENPLADES, 2013). Desde entonces las acciones gubernamentales, como la explotación petrolera y la agroindustria, están enfocadas en el Buen Vivir. Por otro lado, el discurso del Sumak Kawsay, potenciado por parte de los intelectuales indígenas y no indígenas, ha sobrepasado las fronteras, porque supone una alternativa al discurso eurocentrista de carácter antropocéntrico. Sin embargo, y aunque la inversión en educación, salud e infraestructura por parte del gobierno es reconocida a nivel internacional, la decisión de intensificar la megaminería y la explotación del Yasuní ha sido, duramente, cuestionada, justamente por alejarse del Sumak Kawsay. De igual manera, el discurso pachamamista del Sumak Kawsay ha sido puesto en tela de juicio por su carácter utópico y poco pragmático, alejado de la realidad, y por querer hacer creer que los indígenas ha hecho una filosofía propia, parangonándola con la occidental.

La Secretaría Nacional de Planificación y Desarrollo, SENPLADES, (2013) menciona que el Sumak Kawsay se basa en las concepciones pachamamistas ${ }^{2}$. Estas concepciones plantean el convivir en armonía con la naturaleza con el fin de evitar su destrucción (Choquehuanca, 2010). De igual manera, estos enfoques buscan contrarrestar el capitalismo, puesto que en la convivencia comunitaria, tal como supone, todos ganan (De Sousa, 2010). Por otra parte, el Sumak Kawsay intenta potenciar el tiempo libre para la contemplación y ejercicio de libertades plenas, para que los individuos realicen sus proyectos de vida dignamente (Ramírez, 2010). Por estos motivos, este fundamento es considerado como la filosofía de vida que enfrenta al pensamiento utilitarista del liberalismo (Ramírez, 2010); de ahí que, el Sumak Kawsay es presentado como propuesta filosófica y política, volviéndose necesaria en la práctica política y filosófica.

Lo que el presente artículo busca demostrar es la poca viabilidad del $\mathrm{Su}$ mak Kawsay, el mismo que, pese a sus fundamentos, en Ecuador está sustentado desde un discurso idílico. Pues bien, el Gobierno no ha podido im-

2 "Pachamamismo es un término derivado de la deidad andina Pachamama, conocida como "la madre tierra". El - ismo añadido a Pachamama manifiesta "una filosofía, una agenda política, un programa pedagógico, una estética y un marco legal que define perspectivas no occidentales, para una reflexión sobre la intersección entre la naturaleza y la cultura" (Cuelenaere, 2011, p. 185). 
plementar dicho fundamento en toda su magnitud, por lo que la sociedad debe enfrentar a emergencias sociales, alejándose así de la vida en armonía. Por otro lado, el afán de los intelectuales indígenas y no indígenas por demostrar que la cultura andina ancestral tuvo filosofía propia, con ventajas a la occidental, conlleva a contrastar dos formas de pensamiento distinto en tiempo y espacio. Esta situación, en lugar de generar un pensamiento propio desde lo andino, construye una idea filosófica andina yuxtapuesta a la occidental, la misma que es entendida como una oposición.

Para justificar lo dicho anteriormente, se sustentarán las prácticas políticas más sobresalientes del Gobierno, las mismas que se alejan de las propuestas del Sumak Kawsay. De igual manera, se reflexionará sobre las diversas críticas en favor y en contra del este postulado, con el fin de demostrar los argumentos que no son, estrictamente, filosóficos; más bien, este artículo considera que están alejados de la realidad. En definitiva, se pretende responder a la siguiente pregunta: ¿obviar los principios del Sumak Kawsay en la praxis política responde a un planteamiento filosófico idílico de la cosmovisión andina?

Por lo tanto, el objetivo del presente artículo es analizar, de manera crítica, la construcción discursiva del Sumak Kawsay, la misma que se rige como una propuesta política y filosófica de la vida andina en Ecuador. En este sentido, se pretende responder a tres objetivos específicos: 1) estudiar la genealogía de la construcción del discurso del Sumak Kawsay en el contexto ecuatoriano; 2) contrastar los preceptos de este fundamento con ciertas políticas que se distancian de la alternativa al desarrollo convencional, por parte del gobierno ecuatoriano; y 3) analizar la fundamentación filosófica del Sumak Kawsay en sentido estricto.

\section{Aspecto metodológico}

Para desarrollar este artículo se ha visto necesario utilizar el método de análisis exploratorio. En este sentido, se analizarán las diferentes propuestas a favor y en contra del Sumak Kawsay como discurso político y su validez como filosófico. Así mismo, interesa conocer en qué contexto nace el $\mathrm{Su}$ mak Kawsay, qué actores fueron protagonistas, y los motivos que les llevó a fundamentar como filosofía de vida o filosofía andina, a tal punto de llegar a ser el eje transversal de la política del Estado ecuatoriano. Sin embargo, han surgido críticas que cuestionan la validez de la construcción del discurso del 
Sumak Kawsay como filosofía, ya que la filosofía tiene un aspecto fundamental para su desarrollo: la razón. En este sentido, este artículo busca una reflexión crítica de la validez de este discurso como filosofía en sentido estricto y su alejamiento en la praxis política.

\section{Contexto en el que surge el Sumak Kawsay como propuesta política}

El Sumak Kawsay surge como una propuesta alternativa al capitalismo. Por consiguiente, se tomará como punto de partida el retorno a la democracia en la década de 1980 en Ecuador.

Por esta época, el Buen Vivir, aparece como una alternativa al desarrollo convencional, pero como discurso reivindicativo aparece al momento en que se intensificaron los ajustes de las políticas neoliberales de las décadas de 1980 y 1990. Según Saltos (2001) fue cuando los movimientos indígenas en Ecuador plantearon un cambio civilizatorio. En 1992 Alberto Taxo empieza hablar de la economía runa, que proviene de la cosmovisión indígena: "lograr un 'equilibrio' entre los seres humanos y entre éstos y la 'pacha mama' o madre naturaleza" (Cortez, 2011, p. 7).

En 1997 la CONAIE ${ }^{3}$ presentó un Proyecto Político. Cortez (2011, p. 9) señala que en dicha propuesta se discute: "[...] los pueblos y nacionalidades indígenas practicamos [...] un humanismo integral donde el hombre, la naturaleza y el cosmos en estrecha y armónica interrelación garantizan la vida".

En el año 2004 el Buen Vivir se convirtió en el centro de la propuesta educativa. Básicamente, se pregonó una educación en constante armonía con la Pachamama y regida por la economía comunitaria como eje del desarrollo: "el conjunto armónico de relaciones sociales, culturales y naturales se acuñan en el concepto Kawsay, vida, como expresión de una vida plena o bien vivir" (Cortez, 2011, p. 10). Este proceso fue formado en la Constitución del 2008, convirtiéndose el Sumak Kawsay, o Buen Vivir, en el eje transversal de la Constitución del 2008, con el objetivo de emprender políticas en aras de una sociedad post-capitalista y post-colonial (Cortez, 2011, p. 11).

3 Confederación de Nacionalidades Indígenas del Ecuador. 


\section{Concepciones sobre el Sumak Kawsay}

El Sumak Kawsay se oficializa como política de Estado en el 2008, luego de haber sido considerado en la nueva Constitución del Ecuador. En ese sentido, tanto La Carta Magna y el Plan Nacional del Buen Vivir, PNBV, del 2009 y 2013, se fundamentan en los preceptos de esta concepción, en el que claramente se menciona: "los pueblos indígenas andinos aportan a este debate desde otras epistemologías ${ }^{4}$ y cosmovisiones y nos plantean el Sumak Kawsay, la vida plena" (SENPLADES, 2013, p. 32). Uno de los aspectos principales que sirve como base para la planificación en el PNBV, es que el Sumak Kawsay parte de: "la relación armónica entre los seres humanos y con la naturaleza" (SENPLADES, 2013, p. 34). Con el tiempo se empieza a hablar del Socialismo del Buen Vivir en el PNBV del 2013. Este socialismo se funda en: "el Buen Vivir o Sumak Kawsay que construye sociedades solidarias que viven en armonía con la naturaleza" (SENPLADES, 2013, p. 23). Ahora bien, este plan se asocia al Vivir Bien que planteaba Aristóteles, en donde se manifestaba el último fin del ser humano es ser feliz, entiéndase como eudemonismo. En consecuencia, se presume que el Sumak Kawsay busca el mismo fin.

Los argumentos citados en el PNBV concuerdan con el discurso del $\mathrm{Su}$ mak Kawsay sustentados por intelectuales indígenas y no indígenas desde la cosmovisión andina. Por ejemplo, para el indígena boliviano Huanacuni (2010) la cosmovisión andina asume a la comunidad como estructura social inmersa en la naturaleza, donde los seres humanos y los elementos de la naturaleza se relacionan con respeto, porque todo tiene vida. Así mismo, Choquehuanca (2010) busca recuperar las costumbres ancestrales en las que se basa la vida, es decir: "en completa armonía y respeto mutuo con la madre naturaleza, con la Pachamama, donde todo es vida, donde todos somos uywas, criados de la naturaleza y del cosmos". Por otro lado, se puede explicar el Sumak Kawsay en conformidad a las costumbres del homo contemporáneo, así pues, Ramírez (2010, p. 11) indica:

4 Es importante aclarar el término epistemología. Se usa el término epistemología para designar la teoría del conocimiento cuando se refiere a las ciencias. En cambio, la gnoseología trata de la teoría del conocimiento, en tanto que conocimiento humano en general (Mora, 1964). Por lo tanto, hablar de epistemología y cosmovisiones andinas no tienen correlación. 
El Buen Vivir o Sumak Kawsay supone tener tiempo libre para la contemplación y la emancipación, y que las libertades, oportunidades, capacidades y potencialidades reales de los individuos/colectivos se amplíen y florezcan de modo que permitan lograr simultáneamente aquello que la sociedad, los territorios, las diversas identidades colectivas y cada uno -visto como un ser humano/colectivo, universal y particular a la vez- valora como objetivo de vida deseable (tanto material como subjetivamente, sin producir ningún tipo de dominación a un otro).

Además, el Sumak Kawsay parte de la idea de que la naturaleza es parte de la historia (Dávalos, 2008), dado que dentro de la cosmovisión andina ésta es parte de la comunidad, entendiéndose como una estructura social. En efecto, Quijano (2014) sostiene que esta forma de pensar contrapone al paradigma mecanicista cartesiano, en el que se separa la res cogitans de la res extensa, dando como resultado la separación del sujeto con la naturaleza. Ahora bien, la incorporación de la naturaleza en la historia no puede ser vista como objeto de producción, sino como un ente vital, espiritual y cosmológico de la vida humana y de todo lo que existe en el planeta.

Por otro lado, al referirse al Buen Vivir o Sumak Kawsay, Ramírez (2010,p. 7) propone que la naturaleza debe valorarse como: "objeto de vida deseable". De esta forma se contribuye a un cambio de paradigma en las relaciones de las estructuras sociales, ya que: "se da sin producir ningún tipo de dominación a otro" (Ramírez, 2010, p. 7). Por su parte, Acosta (2010) presenta al Buen Vivir como la puerta de la descolonialidad del poder eurocéntrico. El autor menciona: "la lucha contra el modelo de desarrollo capitalista se basa en la acumulación incesante del capital" (2010, p. 9). De esta forma se puede enlazar con la propuesta biocéntrica del Sumak Kawsay, que echa por la borda al proyecto neoliberal, antropocéntrico por antonomasia, que se sustenta en el mercado y el bienestar del producto del esfuerzo individual (Ramírez, 2010). Según Gudynas (2011) el Buen Vivir rompe con la idea de progreso en el que se basa el desarrollo convencional, es decir, se distancia del socialismo marxista clásico. Pues, el Sumak Kawsay considera a la naturaleza como sujeto de valor por ser parte de la comunidad como estructura social. Esto supone construir otra ética para establecer valores, los que se alejan de la ética occidental de modelo kantiano, en la que, los únicos que tienen dignidad son los seres humanos por estar gobernado por la razón (O’Neill, 1995). 
En otras palabras, se puede decir que el Sumak Kawsay es un discurso contestatario al sistema capitalista. A esto se debe recurrir a las consideraciones indicadas por Amartya Sen (2000), quien aboga por un desarrollo centrado en las libertades humanas, más que en el crecimiento económico. Así mismo se podría acudir a Latouche (2008), quien defiende la tesis del decrecimiento como alternativa al sistema capitalista, basado en las nociones de desarrollo y progreso. Y es que así como el Sumak Kawsay tiende a radicalizar su propuesta al sustentar una postura biocéntrica, en la que la economía solo es un medio y no un fin, y, se organiza en base a las leyes naturales y no económicas (Acosta, 2010). Sin embargo, y pese a ser una propuesta difundida y defendida dentro y fuera del continente, no logra reflejarse en la praxis.

\section{El Sumak Kawsay atrapado en el sistema desarrollista en Ecuador}

Las contribuciones respecto al Sumak Kawsay han sido sustentadas por múltiples autores, tanto nacionales como internacionales. Tal es la importancia que tomó el tema, que en el PNBV se tomó como punto de partida y respaldo para su construcción. En dicho plan, la SENPLADES (2013, p. 23) manifiesta:

El debate alrededor del Sumak Kawsay ha rebasado las fronteras ecuatorianas y latinoamericanas, ha impulsado la reflexión política y académica y ha recogido los aportes de movimientos sociales, académicos, líderes políticos y gestores de política pública. Se trata de una noción en permanente construcción.

Sin embargo, esa noción en proceso no parece emerger del indígena propio. Precisamente, Bretón, Cortez y García (2014) demuestran cuán alejado está este discurso de la realidad del común de la gente. Los autores preguntaron a un habitante de la comunidad Salasaca de la provincia de Tungurahua, sobre su opinión acerca del reconocimiento del Sumak Kawsay en la Constitución del 2009, la repuesta fue intrigante: “¿qué cosa será el Sumak Kawsay"? (Bretón, Cortéz, \& García, 2014, pp. 10-11). Esta frase, aparentemente ingenua revela la inviabilidad del Sumak Kawsay en la praxis política.

No obstante, la SENPLADES (2013, p. 32) no duda en plantear al Sumak Kawsay como el camino para el cambio de paradigma, cuando expresa: "el nuevo pacto de convivencia sellado en la Constitución del 2008, este 
Plan propone un desplazamiento de la palabra desarrollo ${ }^{5}$ para incorporar en el debate el concepto del Buen Vivir". Pero las políticas implementadas sobre la minería, la explotación petrolera y los agronegocios, han sido cuestionadas, justamente, por no salir del desarrollismo e incorporar lo antes citado. Más bien, parece abandonar lo que se enuncia en el preámbulo de la Constitución del 2009: "decidimos construir una nueva forma de convivencia ciudadana, en diversidad y armonía con la naturaleza, para alcanzar el buen vivir, el Sumak Kawsay [...]" (SENPLADES, 2013). A continuación se revisará cada una de las políticas propuestas en este artículo, que atentan contra el Sumak Kawsay.

\section{Política minera}

Resulta que, mientras se glorifica y se enarbola el pasado del indígena andino, las políticas implementadas entorno a la minería han sido las que atenta a los pueblos indígenas. Ospina (2013, p. 28) señala: "el 5 de marzo el gobierno de la revolución ciudadana firmó el primer contrato de minería metálica a gran escala en el Ecuador con la empresa de capitales chino-canadienses Ecuacorrientes S.A. por 25 años". Este hecho hizo que la CONAIE y otros actores se sumaran a las protestas contra el régimen. Y es que, el conflicto no es solo social y ambiental, sino, con el discurso alrededor al Sumak Kawsay con el que se configuró la constitución y el PNBV en los dos periodos 2009 y 2013.

El propósito de la minería es sacar recursos para la inversión social, lo cual, no es una idea descabellada. Pero, si la aspiración política era propiciar el Sumak Kawsay ¿cómo se entiende su materialización cuando se dan desalojos en la Amazonía? Según Diario El Universo (2015), diez familias fueron desalojadas en Tundayme, provincia de Zamora Chinchipe. Para el régimen este hecho se justificó al permitir alcanzar el Buen Vivir, sin embargo, para los habitantes de las zonas aludidas significó contaminación del agua y pérdida de sus territorios. Ante esta disyuntiva del gobierno con los pobladores de Tundayme, la frase interrogatoria del indígena salasaca: “¿qué cosas será el Sumak Kawsay?" se vuelve relevante frente a la retórica pachamamista presente en la Constitución del 2009 y en el PNBV.

5 "Llámese desarrollo convencional al que se basa en el crecimiento económico, para a partir de allí propiciar bienestar a la sociedad" (Morocho, 2013, p. 2). 


\section{Política petrolera}

Por otro lado, la explotación petrolera es otro de los temas que ha despertado polémica. Las manifestaciones y los debates se intensificaron al momento en el que el Gobierno autorizó la explotación petrolera en el Parque Nacional Yasuní.

En principio, el Gobierno sugirió dejar bajo tierra el petróleo del parque Yasuní ${ }^{6}$, creando expectativas a nivel internacional. Así pues, el proyecto encajaba frente a la crisis del cambio climático, entre esta se encontraban los débiles acuerdos para combatir la emisión de gases de efecto invernadero, esto por parte de los países más ricos en la Cumbre de Copenhague en el 2009 (Le Quang, 2013). Para llevar a cabo dicho proyecto, el gobierno pidió financiamiento de los países industrializados. Sin embargo, ante la negativa, se puso en marcha el plan B, dejando inválida la iniciativa tan aclamada por su radicalidad: “idejar el petróleo bajo tierra con el fin de evitar la emisión de gases de efecto invernadero, y proteger a las poblaciones indígenas de la región así como su biodiversidad!" (Le Quang, 2013, p. 11). Por dichas razones, se puede señalar que el proceso de permanente construcción del Sumak Kawsay, expresado en la SENPLADES (2013) y en Acosta (2010), quedó truncado.

Retomando la pregunta del indígena salasaca "¿qué cosa será el Sumak Kawsay?" (Bretón, Cortéz, \& García, 2014, pp. 10-11) lleva a reflexionar sobre el discurso que se maneja a nivel político, como si efectivamente se practicara el Buen Vivir o Sumak Kawsay. ¿Qué mismo será? Si se supone que, para poder aprobarse, la Constitución recogió las aspiraciones de pueblos y nacionalidades entorno al Sumak Kawsay, su materialización hasta hoy no camina hacia un cambio de paradigma anti desarrollista. Otro ejemplo de la política gubernamental que se aleja del Sumak Kawsay, gira en torno al sector del agronegocio.

\section{Política del agronegocio}

En cuanto al agronegocio, Ecuador continúa con la misma lógica del Cono Sur. Por citar un caso, Bravo (2010) dice que el agronegocio en Argentina, en base al cultivo de la soja, ha significado la apropiación de tierras y acaparamiento del agua por parte de los señores de la soja; como resultado

6 El proyecto se llama la Iniciativa Yasuní-ITT, sigla que proviene de los nombres de las perforaciones para explotar el petróleo en la zona: Ishpingo, Tambococha, Tiputini. 
están los “impactos socioculturales y económicos para los indígenas y campesinos. De manera semejante, en Ecuador, según Houtart (2014), la agricultura familiar campesina tiene grandes inequidades frente al agronegocio. Al respecto, el autor manifiesta: "según el Censo Agrario, en el Ecuador el 37\% de unidades de agricultura familiar campesina tiene acceso al riego, frente al $63 \%$ de la agricultura empresarial" (2014, p. 171). Es decir, el agro ecuatoriano se trata de monocultivos, casi de manera exclusiva, para la exportación, tales como: banano, brócoli, palma africana, caña de azúcar, piñón, etc.

Diario El Telégrafo en el 2014, citado por Houtart (2014), mencionó que en el 2012 el $46.5 \%$ de las áreas cultivadas eran destinadas a estas actividades con proyecciones de incremento. Así mismo, para la producción de etanol se destinaron 40 mil hectáreas. El problema de los monocultivos, además de la captación de agua y tierra, es que contaminan por el excesivo uso de químicos que terminan agotando los suelos. Además, en un estudio sobre el agronegocio del brócoli, han demostrado que el impacto sobre la reducción de la pobreza es casi nulo (Houtart \& Yumba, 2013).

Finalmente, se puede indicar que estas políticas desarrollistas ilustran cuán separadas están de la política gubernamental del discurso del Sumak Kawsay. Sin embrago, sería inoportuno desmerecer las grandes inversiones que el gobierno ha realizado en educación, salud, vialidad, entre otros. Pero, fijándose en el tema del Buen Vivir, si la consigna era recuperar las costumbres ancestrales andinas, cuya relación con la naturaleza es en armonía, la política petrolera, megaminería y del agronegocio, no responden a la cosmovisión andina. Resultaba más congruente hablar de un capitalismo moderado del Siglo XXI y no del Sumak Kawsay o Buen Vivir.

En definitiva, el desarrollismo tal como se ha visto hasta ahora, y el Sumak Kawsay, como propuesta para un cambio de paradigma ${ }^{7}$, quedan como meros discursos políticos. Un discurso que aparenta emerger de los múltiples aportes de organizaciones sociales indígenas y no de indígenas, propiamente dicho. Pues, para el comunero salasaca resulta extraño a su realidad, dejando en duda los argumentos sobre el rescate de la cosmovisión andina que propicia un cambio de paradigma, con ventajas ostensibles sobre el pensamiento occidental, como se verá en el siguiente acápite.

7 El cambio de paradigma se refiere a dejar el sistema capitalista en lo económico y el neoliberalismo en lo político. Significa, dejar atrás la ida del estado-nación con una sola lengua, un solo pensamiento. Es decir, esa idea de uniformidad. El fin es pasar a un Estado plurinacional e intercultural. 


\section{El Sumak Kawsay: razón desde la cosmovisión andina pero no filosofía en sentido estricto}

IAhora, recordando la frase del indígena salasaca ¿qué cosa será el $\mathrm{Su}$ mak Kawsay?, se reflexionará el discurso del Sumak Kawsay entorno a la filosofía. Pues bien, si en la praxis política el Sumak Kawsay está distante de sus preceptos, conviene examinar la parte filosófica, ya que, intelectuales indígenas y no indígenas le han denominado como pachasofía; por lo tanto, ¿será filosofía lo que practicaron los ancestros andinos?

Aunque el Sumak Kawsay se ha traducido oficialmente como Buen Vivir, Oviedo (2013, p. 30) cuestiona dicha traducción, según él: “Alli Kawsay es Buen Vivir/Vivir Bien, y Sumak Kawsay es Convivir en Armonía y Límpido". Por tal razón, para efecto de este artículo, se empleará el término Sumak Kawsay.

Dentro de ese marco, y respecto a los fundamentos sobre el Sumak Kawsay desde las posiciones indigenistas, Macas (2010), Maldonado (2010) y Oviedo (2013) expresan que debería ser una filosofía de vida, la que se base en la herencia ancestral de las comunidades y pueblos indígenas. De igual manera, los autores concuerdan con que la filosofía indígena orienta a los seres humanos a convivir con la naturaleza antes que destruirla, puesto que se rigen en los principios de comunidad en armonía entre seres humanos y la naturaleza. Por otro lado, también se habla de recuperar la cultura de la vida, aquella que vivía en completa armonía con la Pachamama, es decir, el hombre se consideraba criado de la naturaleza y del cosmos (Choquehuanca, 2010).

De igual manera, Estermann (1998), se refiriere e a la cosmovisión andina como: "estudio intercultural de la sabiduría autóctona andina". El autor se refiere a la cultura andina como propia de pachasofía, cuyos postulados entonan con los principios del Sumak Kawsay, el autor también habla de ecosofía andina como:

El hombre andino no ve a la naturaleza desde un punto de vista económico sino ecológico, no la concibe en una relación de oposición a sí mismo, sino que la entiende como formando él mismo parte de ella. La ecosofía se muestra también como una ética: el ser humano no puede abusar de la naturaleza sino que tiene que obedecer a la relacionalidad ordenada en ella (Sobrevilla, 2008, p. 236).

En efecto, el Sumak Kawsay, sustentado como filosofía de vida, gira en torno a una posición naturalista. En ese sentido, para argumentar como prác- 
tica filosófica se empieza a correlacionar con el pensamiento occidental. Al respecto, Oviedo (2013) dice que los filósofos Milesios, considerados naturalistas, serían los únicos que practicaron una verdadera filosofía, puesto que el principio de todas las cosas, arjé, se sustentaba en los elementos de la naturaleza, por ejemplo: para Tales era el agua, para Anaxímenes el aire y para Anaximandro el ápeiron, lo que no posee forma, es infinita e indeterminada. A estas concepciones, el autor las reconoce como filosofía ancestral, y que desaparecieron a raíz de la idolatría de la razón, por parte de los filósofos que precedieron a los naturalistas.

Hasta aquí el esfuerzo de Oviedo (2013) y de Estermann (1998), al comparar la cosmovisión andina con la filosofía occidental, da a entender que los antepasados andinos hicieron filosofía. Por lo tanto, el Sumak Kawsay, presentado como filosofía de vida, se considera el paradigma a recuperarse, en virtud de que los ancestros vivían en armonía, tanto con la naturaleza y la comunidad. Tal es el afán por demostrar al Sumak Kawsay como una propuesta filosófica en contra a la occidental, por lo que se ha tornado en una concepción pomposa, casi mistificarla. Como muestra, Ramírez (2010) la denominó "bioigualitarismo republicano".

Con esta mistificación el discurso del Sumak Kawsay acarrea dos aspectos: 1) considerarse erróneamente como filosofía a la cosmovisión andina y, 2) alejarse de la realidad. En primer lugar, llamarlo filosofía de vida, filosofía andina, pachasofía o filosofía indígena, sin distinguir el pensamiento filosófico del no filosófico, conlleva a una concepción desprendida, de lo que realmente pudo haber sido el Sumak Kawsay como forma de vida de las poblaciones ancestrales andinas. No hay que olvidar que la filosofía de los Milesios empezó con la razón de carácter objetiva; según Aristóteles, ya que afrontaron el problema del arjé en términos racionales y no míticos. En efecto: "la filosofía empieza cuando el pensamiento deviene racional" (Mosterín, 2006, p. 565).

Para Sobrevilla (2008, p. 233), el pensamiento andino no trasciende del mundo mítico, puesto que no reflexiona la realidad, es decir: "el runa andino siente la realidad antes que la conoce o la piensa". Por lo tanto, no se puede considerar filosofía estrictamente, más que en el sentido amplio por las interpretaciones sobre el universo o de Dios, manejado dentro del campo, del credo y del mito.

Por otra parte, Viola (2014, p. 64) manifiesta: "una versión idealizada de la cosmovisión y de los valores de las culturas andinas". Esta situación no 
hace más que alejarla de la realidad, y como muestra se puede citar el asombro del indígena salasaca cuando dijo: “¿qué cosa será el Sumak Kawsay?" Se sabe que la CONAIE (1997) y la Universidad Intercultural Amawtay Wasi (2004) divulgaron el Buen Vivir como posibilidad para un cambio civilizatorio, y que después fue tomado en cuenta para la construcción de la Constitución del 2008. Sin embargo, y a pesar de que hubo mesas de discusión, quienes redactaron el documento definitivo fueron un sinnúmero de asesores y consultores internacionales, muchos de ellos, alejados de la realidad,- de esta forma terminaron con un concepto más allá de un modo vivendi indígena, rebasando la propuesta de los grupos indígenas.

\section{La inconmensurabilidad del Sumak Kawsay con la filosofía occidental}

Ahora bien, esta analogía entre la cosmovisión andina con la filosofía occidental conlleva a un estado de inconmensurabilidad. La inconmensurabilidad, según Kuhn (1962), se produce cuando dos paradigmas se tornan distantes, por cuanto divergen en la manera de ver e interpretar el mundo. Como muestra, para Ptolomeo el sol y la luna eran considerados planetas girando alrededor de la tierra, mientras que para Copérnico la tierra era un planeta que gira alrededor del sol (Kuhn, 1962, citado por Moreno, 1995, p. 445). En este caso, dos maneras de ver el mundo bajo la lupa de la razón se vuelven incompatibles. Volviendo al tema, se ve que el mundo andino con el occidental difiere, abruptamente, en la forma de ver y de interpretar la realidad.

En relación al mundo andino, está asentado en lo arcaico y no en lo racional; según el filósofo Mosterín (1990, p. 242) lo arcaico se caracteriza por lo siguiente:

1) se trata de un pensamiento que va directamente a su objeto sin considerar su propio condicionamiento subjetivo, lingüístico o metódico, 2) trata a todos los fenómenos como un tú personal que compromete al sujeto emocionalmente, y no como un ello objetivo y despegado del sujeto, 3) dicho pensamiento personaliza a los fenómenos que observa y los hipostatiza como supra entidades personales, espíritus o dioses, y no los analiza conceptualmente, 4) el asombro que producen en el sujeto los fenómenos que llaman su atención lo mitiga mediante la elaboración de mitos y no mediante la construcción racional de teorías, 5) el sujeto busca sobornar a los dioses mediante 
cuidados, cultos, ofrendas etc. a fin de obtener sus favores, y 6) la ansiedad por el futuro da lugar a la adivinación para conocer cómo ha de presentarse.

Respecto al mundo occidental, la filosofía tiende al estudio teórico de la realidad desde sus inicios, basándose en: "la tesis de la diferencia entre la apariencia y la realidad se hizo cada vez más acentuado en el pensamiento griego" (Mora, 1964, p. 173). Por lo tanto, al no tomarse en cuenta la inconmensurabilidad del mundo andino con el occidental, cuando se expone la cosmovisión andina como si fuera filosofía, se termina hibridando palabras como pachasofía. Dicho de otra manera, cuando se usa el término filosofía, para validar el pensamiento andino, es como si se asumiera la influencia occidental, después, para negarla al mismo tiempo.

En virtud de lo antes expuesto, el planteamiento del Sumak Kawsay, como filosofía de vida, denota una falta de originalidad al compararla con la occidental. En efecto, a Sobrevilla (2008, p. 239) le parece: "surgen más bien del ánimo de probar que la cultura andina posee una filosofía vigorosa con ventajas perceptibles sobre la filosofía occidental". De ahí que hay cuestionamientos por su falta de pruebas.

\section{Tabla 1}

\section{La razón andina y razón occidental}

\begin{tabular}{|l|l|}
\hline \multicolumn{1}{|c|}{ Razón desde la cosmovisión andina } & \multicolumn{1}{c|}{ Razón desde la occidental } \\
\hline $\begin{array}{l}\text { Dicho pensamiento personaliza a los } \\
\text { fenómenos y los hipostatiza como supra } \\
\text { entidades personales, espíritus o dioses. }\end{array}$ & $\begin{array}{l}\text { Regularmente analiza conceptualmente los } \\
\text { fenómenos }\end{array}$ \\
\hline $\begin{array}{l}\text { Trata a todos los fenómenos como un } \\
\text { tu personal que compromete al sujeto } \\
\text { emocionalmente. }\end{array}$ & $\begin{array}{l}\text { Trata a los fenómenos como un ello objetivo } \\
\text { y despegada del sujeto: pero también persiste } \\
\text { elementos como leyendas. }\end{array}$ \\
\hline $\begin{array}{l}\text { El asombro que producen en el sujeto los } \\
\text { fenómenos los aborda a través de mitos. }\end{array}$ & $\begin{array}{l}\text { El asombro de los fenómenos los aborda a través } \\
\text { de la construcción nacional de teorías a pesar de } \\
\text { que el mito aún está presente. }\end{array}$ \\
\hline $\begin{array}{l}\text { El sujeto busca sobornar a los dioses mediante } \\
\text { cuidados, cultos, ofrendas, etc. A fin de obtener } \\
\text { sus favores. }\end{array}$ & $\begin{array}{l}\text { Regularmente, en el pensamiento a través de la } \\
\text { razón no apela a lo sobrenatural... }\end{array}$ \\
\hline $\begin{array}{l}\text { Busca conocer el futuro a través de la } \\
\text { adivinación }\end{array}$ & $\begin{array}{l}\text { Normalmente recurre a la investigación } \\
\text { denominada científica en el mundo formal. }\end{array}$ \\
\hline
\end{tabular}

Fuente: El Autor 


\section{El Sumak Kawsay distante de la realidad}

A estas alturas del presente artículo, es necesario conocer el vínculo real del Sumak Kawsay con las culturas ancestrales actuales. En este sentido, tres estudios intentan demostrar la contextualización del Sumak Kawsay con el mundo ancestral, pero no logran más allá de una idealización científica.

El primer estudio fue realizado por Rengifo (2002), en donde se recogen vivencias y testimonios de las comunidades campesinas quechuas y aymaras del Perú. El segundo y tercer estudio fueron ejecutados por Viteri en el año 2000 y 2003, en donde se constataron y sistematizaron las vivencias del pueblo kichwa amazónico ecuatoriano de Sarayaku (Viteri, 2000; 2003). Gracias a los aportes de Viteri, Hidalgo (2014) comparó los dos estudios y opina que no pasa de ser un collage andino de bienestar, por cuanto: "hacen emerger, por medio de un proceso de percepción, como fenómeno social objeto de conocimiento científico" (Hidalgo, 2014, p. 34). Por lo tanto, no hay una constatación efectiva de la práctica del Sumak Kawsay como eje transversal de las comunidades indígenas. Quizá sea una de las razones por lo que el indígena salasaca respondiera: “¿qué cosa será el Sumak Kawsay? De este modo, intentar instalar el discurso del Sumak Kawsay como filosofía andina parece estar lejos de la vivencia cotidiana. La ausencia de pragmatismo en la realidad responde a esa construcción romántica del Sumak Kawsay como discurso filosófico.

Presentarle al Sumak Kawsay como un paradigma de vida cuyos principios rigen en la convivencia armónica entre los seres humanos y entre éstos con la naturaleza, se torna dudoso y alejado de la realidad. Da la sensación de que no había problemas entre los pueblos andinos en la época precolombina, cuyas estructuras sociales parecían ser tan igualitarias que, incluso, sobrepasan las expectativas del comunismo marxiano cuando se lee a muchos autores y pensadores que se han analizado en este artículo.

Sin embargo, Paz y Miño (2015) habla sobre el sometimiento de los grupos indígenas por parte de los incas, ya sea por conquista, alianza o subordinación. Si bien es cierto, continúa el autor, no tenían el sentido de propiedad como hoy, pero todo era del Inca, y los miembros de las comunas eran propietarios, y no al mismo tiempo, de la tierra. No cobraban impuestos como hoy, pero aprovechaban la fuerza laboral obligatoria de los conquistados para su propia subsistencia y la del Imperio. Sus prácticas políticas, económicas y sociales no se asentaban en lo socialista ni en lo comunista, pero a 
esto han asociado al Sumak Kawsay en la actualidad. Por esto es necesario reflexionar sobre el discurso del Sumak Kawsay para tener una propuesta más cercana a la realidad, y no una retórica llena de expectativas utópicas que no logran reflejarse en la práctica.

\section{Conclusiones}

La primera conclusión a la que llega le presente estudio está relacionada al discurso del Sumak Kawsay que emerge de las organizaciones indígenas en Ecuador. Nace como una posibilidad de cambio civilizatorio ante el fracaso de las políticas neoliberales de la década de 1980 y 1990. Básicamente se plantea una economía que logre un equilibrio entre los seres humanos y su relación con la madre naturaleza. Sin embargo, los postulados sobre el Sumak Kawsay recogidos en la Constitución del 2008 y expandido por intelectuales indígenas y no indígenas fuera del país, hasta ahora, no logran materializarse en la realidad como política pública. Y es que ante la realidad social a la que se enfrenta el Sumak Kawsay, como la pobreza, acceso a la salud, a la educación, a la vivienda, entre otros, que gran parte de la población históricamente ha carecido, hablar del Sumak Kawsay tal como se ha visto, se vuelve estéril. Por lo tanto, no hay un planteamiento claro de cómo proceder para hacerle cara a los problemas de la realidad social.

Por otra parte, el Gobierno usa el término Buen Vivir para referirse a la política pública implementada hasta ahora. Pero al promover tres políticas: megaminería, agronegocio y explotación petrolera, propias del desarrollo convencional, no se ajusta a los principios del Sumak Kawsay. En efecto, el Sumak Kawsay queda como un mero marketing político, una estrategia de cambiar el discurso del bienestar social, occidental, por uno de corte andino.

También se puede decir que la construcción discursiva del Sumak Kawsay debe someterse a una autocrítica que reconstruya una propuesta desde abajo y que se refleje en la realidad. Como se aborda ahora, demuestra una contradicción al desprestigiar a la razón, y al mismo tiempo, tomar su términos para autoproclamarse como una propuesta mejor. La respuesta y a la vez pregunta del indígena salasaca es una clara muestra de la desconexión; primero, entre las élites intelectuales indígenas y su gente de a pie; segundo, con el régimen que ha tomado prestado este discurso para justificar sus acciones, como si se tratara de algo innovador ante las prácticas neoliberales del pasado. 
Esta presunción de fundamentar como si los indígenas precolombinos hubieran practicado una filosofía propia, parangonándola con la occidental, no permite evidenciar la realidad de las culturas ancestrales indígenas. Los ancestros no hicieron filosofía propiamente dicha, puesto que su mundo fue arcaico. No es que sea menos ni más que la razón por ser así, pero es donde se tiende a errar. Por lo tanto, argumentar comparando con el pensamiento occidental hasta el punto de realizar una hibridación de palabras no le hace mejor, ni más eficaz en la praxis para confrontar los problemas contemporáneos.

Pues bien, la filosofía nace con la razón y es lo que la hizo diferente del pensamiento arcaico, que se basaba en lo mítico para explicar la realidad. Por consiguiente, adjetivar al pensamiento andino cuando se dice "filosofía andina" para demostrar que los ancestros andinos tuvieron una pachasofía, es querer juntar la razón con el mito. La razón, guste o no es fruto de la curiosidad humana por conocer la realidad. Los ancestros tuvieron la misma curiosidad de conocer el mundo, pero lo hicieron desde lo arcaico y, desde esa perspectiva, interpretaron el mundo como cualquier otra cultura. En efecto, si se quiere valorar y recuperar el pensamiento andino, es mejor partir tratándolo tal como es y sin analogías.

Finalmente, Mejía (2005, p. 246) -quechuista de nota y filósofo andino- sostiene: "suponer que los antepasados de los andinos actuales hicieron filosofía no mejora en nada su condición ni aporta esperanzas para superarla". Es decir, hacer creer que los ancestros tuvieron una filosofía propia y que uno debe estar orgulloso, no es significativo para los pueblos indígenas ante la realidad que ellos viven, por situaciones como pobreza y exclusión. Y es que la mitificación del Sumak Kawsay, presentándola como una práctica de vida ancestral libre de conflictos entre seres humanos y éstos con la naturaleza, conlleva hacerla inviable. En consecuencia, los argumentos ventilados por los intelectuales indígenas y no indígenas dejan un vacío, una duda, frente a la perplejidad del indígena salasaca cuando soltó la frase: “¿qué cosa será el Sumak Kawsay?”. Por lo tanto, hasta se conoce el Sumak Kawsay pero no es filosofía estrictamente, ni parece estar sentado en la realidad. En todo caso, si se trata de un proceso en construcción, hay que tener claridad de ¿quién o quienes están construyendo el Sumak Kawsay? y ¿con qué propósito? 


\section{Bibliografía}

Acosta, A. (2010). El Buen Vivir en el camino del post-desarrollo. Una lectura desde la Constitución de Montecristi. Obtenido de http://library.fes.de/ pdffiles/bueros/quito/07671.pdf

Cuelenaere, L. (2011). Pachamamismo, o las ficciones de la ausencia de voz. Cuaderno de Literatura (32), 185-205.

Bravo, M. (2010). Los señores de la soja. La agricultura transgénica en América Latina. Buenos Aires: CLACSO.

Bretón, V., Cortéz, D., \& García, F. (2014). En busca del Sumak Kawsay. Iconos, 18(48), 9-24.

Cortez, D. (2011). La construcción social del Buen Vivir (Sumak Kawsay) en Ecuador: Genealogía del diseño y gestión política de la vida. Obtenido de http://pluriversidadamawtaywasi.org/images/librosDigitales/LaConstruccionSocialdelBuenVivir.pdf

Choquehuanca, C. (2010). Hacia la reconstrucción del Vivir Bien. América Latina en Movimiento (452), 6-12.

Dávalos, P. (2008). Reflexiones sobre el Sumak Kawsay (Buen Vivir) y las teorías del desarrollo. América Latina en Movimiento.

Diario El Universo (16 de diciembre de 2015). Unas 10 familias desalojadas en Tundayme en operativo de control minero. Obtenido de http://www.eluniverso.com/noticias/2015/12/16/nota/5301738/10-familias- desalojadas-tundayme-operativo-control-minero

De Sousa, B. (2010). La hora de 1@s invisibles. En: Sumak Kawsay/Buen Vivir y cambios civilizatorios (pp. 55-73). Quito: FEDAEPS.

Estermann, J. (1998). Filosofía Andina. Estudio intercultural de la sabiduría autóctona andina. Quito: Abya-Yala.

Gispert, C. (2005). Manual didáctico de autores, textos, escuelas y conceptos filosóficos. Barcelona: Grupo Océano.

Gudynas, E. (2011). Buen Vivir: Germinando alternativas al desarrollo. América Latina en Movimiento (452).

Hidalgo, A. (2014). Seis debates abiertos sobre le Sumak Kawsay. Iconos, 18(48), 25-40.

Houtart, F. (2014). El desafío de la agricultura campesina para el Ecuador. En: La restauración conservadora del correísmo (pp. 167-178). Quito: Arcoíris Producción Gráfica.

Houtart, F., \& Yumba, R. (2013). El brócoli amargo. Ciencias Sociales (35), 283-300. 
Huanacuni, F. (2010). Buen Vivir/Vivir Bien: Filosofía, políticas, estrategias y experiencias regionales andinas. Lima: Coordinadora Andina de Organizaciones Indígenas.

Kuhn, T. (1962). The structure of scientific revolution (2da ed.). Chicago: University of Chicago.

Latouche, S. (2008). La propuesta por el decrecimiento: ¿cómo salir del imaginario dominante? (1era ed.). Barcelona: Icaria.

Le Quang, M. (2013). Dejar el petróleo bajo tierra. La iniciativa Yasuní ITT. Quito: IAEN.

Macas, L. (2010). Sumak Kawsay: la vida en plenitud. América Latina en Movimiento (452), 14-16.

Mejía, M. (2005). Hacia una filosofía andina. Lima.

Maldonado, L. (2010). El Sumak Kawsay/Buen Vivir/Vivir Bien. La experiencia de la República del Ecuador. En: A. Hidalgo, D. Guillém, \& D. Guazha (Eds.), Sumak Kawsay Yuyay: Antología del pensamiento indigenista ecuatoriano sobre Sumak kawsay (pp. 193-201). Quito.

Mora, F. (1964). Diccionario de Filosofía (5ta ed.). Buenos Aires: Editorial Sudamericana.

Moreno, L. (1995). La noción de inconmesurabilidad de Kuhn. Llull Revista de la Sociedad Española de Historia de la Ciencias y de las Técnicas, 18(35), 441-456.

Morocho, S. (2013). Cambio de la matriz productiva: camino al Sumak Kawsay,o al desarrollo convencional. Quito: FLACSO.

Mosterín, J. (1990). Historia de la Filosofía 1. El pensamiento arcaico. Madrid: Alianza.

(2006). El pensamiento arcaico. Historia del pensamiento (Alianza ed.). Madrid.

Ospina, P. (2013). La revolución ciudadana en Ecuador: conflicto social, régimen disciplinario y proyecto de Estado. En: J. Cuvi, D. Machado, A. Oviedo, \& N. Sierra (Eds.), El correísmo al desnudo (pp. 26-33). Quito: Arcoíris Producción Gráfica.

O’Neill, O. (1995). La ética kantiana. En: P. Singer (Ed.), Compendio de ética (pp. 253-266). Madrid: Alianza.

Oviedo, A. (2013). Buen Vivir vs. Sumak Kawsay. Reforma capitalista y revolución aternativa. Una propuesta desde los Andes para salir de la crisis global. Buenos Aires: CICCUS.

Paz y Miño, J. (2015). Historia de los impuestos en Ecuador. Quito: SRI-PUCE-THE. 
Quijano, A. (2014). Buen Vivir: entre el desarrollo y la descolonialidad del poder. En: CLACSO (Ed.), Cuestiones y horizontes: de la dependencia histórico-estructural a la colonialidad/descolonialidad del poder (pp. 847859). Buenos Aires: CLACSO.

Ramírez, G. (2010). Socialismo del Sumak Kawsay o biosocialismo republicano. En: Los nuevos retos de América Latina: Socialismo y Sumak Kawsay (pp. 55-74). Quito: SENPLADES.

Rengifo, G. (2002). Allin Kawsay. El bienestar en la concepción andino amazónica . Lima: PRATEC.

SENPLADES (2013). Plan Nacional para el Buen Vivir 2013-2017. Quito: SENPLADES.

Saltos, N. (2001). Movimiento indígena y movimientos sociales: Encuentros y desencuentros. Obtenido de http://icci.nativeweb.org/boletin/27/saltos.html

Sen, A. (2000). El desarrollo como libertad. Gaceta Ecológica (55), 14-20.

Sobrevilla, D. (2008). La filosofía andina del P. Josef Estermann. Solar (4), 231-247.

Viola, A. (2014). Discursos pachamamistas versus políticas desarrollistas. El debate sobre el Sumak Kawsay en los Andes. Iconos, 18(48), 55-72.

Viteri, C. (2000). Visión indígena del desarrollo en la Amazonía. Polis (3). (2003). Sumak Kawsay. Una propuesta viable al desarrollo. Quito: Universidad Politécnica Salesiana (Tesis).

Fecha de recepción: 9/12/2016; fecha de aceptación: 16/06/2017;

fecha de publicación: 30/06/2017 